\title{
Optimization of the Inclusion of Alzheimer's Disease Patients in International Multicenter Randomized Trials: Results of a National Survey Conducted in Memory Research Centers in France
}

\author{
A.E. Tchalla $a^{a} b$ \\ C. Adam ${ }^{a}$ \\ C. Gayot ${ }^{a, b}$ \\ P. Cowppli-Bony ${ }^{d}$ \\ P.M. Preux ${ }^{c}$ \\ T. Dantoine ${ }^{a, b}$
}

a Service de Médecine Interne Gériatrique, Pôle de Personnes Âgées et Soins à Domicile, Centre Hospitalier Universitaire de Limoges, ${ }^{\text {bEA }} 6310$ HAVAE Handicap Autonomie Vieillissement Activité Environnement, Université de Limoges, and 'IFR 145 GEIST, Institut d'Epidémiologie Neurologique et de Neurologie Tropicale, INSERM UMR 1094 NeuroEpidemiologie Tropicale, Université de Limoges, Limoges, and ' Unité INSERM 897, CMRR d'Aquitaine, CHU, Bordeaux, France

Key Words

Alzheimer's disease $\cdot$ Clinical trials · Inclusion · Optimization

\begin{abstract}
Introduction: Since 2002, with the creation of Centers of Memory Resources and Research (CMRR), considerable progress has been made in France regarding the administrative and institutional framework within which Alzheimer's disease (AD) is managed. In this study, we explore three approaches that can help optimize the inclusion of patients in clinical trials related to $A D$. They are as follows: to assess communication concerning clinical trials on $A D$ in French CMRR, to analyze the internal organization of these centers concerning the dynamics of inclusion, and to evaluate screening tools used. Methods: A national, descriptive, crosssectional survey was conducted in all CMRR in France between May 1 and July 31, 2011, using a self-administered questionnaire. All investigators, subinvestigators and the relevant CMRR personnel were involved. Results: A total of $75 \%$ of the CMRR participated, and about $30 \%$ of the physicians contacted responded positively to the survey. Only $50 \%$ reported having communicated with health care professionals at least once in the previous 3 months, and less than $50 \%$ had communicated occasionally with the general public. A total of $75 \%$ of those surveyed had a research group but only half of the groups were active, $50 \%$ of the physicians did not have a consultation time dedicated to study recruitment, and $75 \%$ of the respondents had a screening tool in their CMRR but over half of them were not satisfied with it. Conclusion: This investigation provides a basis for improving the screening of patients by both internal orga-
\end{abstract}


nizational development and adaptation of tools already available. Improvement requires promoting regular communication that is appropriate and targeted to health care professionals, smaller memory centers, associations and the public, and therefore, familiarizing the whole population with clinical research on AD.

(C) 2013 S. Karger AG, Basel

\section{Introduction}

Dementia is one of the most common and one of the most serious neurological disorders - particularly given the aging population. It is estimated that the number of people with dementia globally increased from approximately 24 million in 2000 to nearly 35.6 million in 2010 , and that this number doubles every 20 years $[1,2]$. Alzheimer's disease (AD) and related dementias represent a major challenge for health care systems in the aging population [1]. AD is particularly devastating in that there is no cure and no way to prevent it or slow its progression. It was estimated that in the USA, at least 11 million of individuals are expected to suffer from AD by the middle of the century and 6 million in Europe [2,3]. In the UK, the number of individuals with dementia is approaching 700,000, with more than half of them suffering from AD [3]. Researchers estimate that by 2050, 115 million subjects will suffer from AD worldwide. Therefore, the estimated AD-related health care costs will become unsustainable. In 2010, the cost of dementia was globally estimated to USD 604 billion $[4,5]$. Moreover, there remains the need to preserve the independence, autonomy and quality of life of elderly subjects with $\mathrm{AD}$ as long as possible and to relieve the burden of care experienced by informal caregivers.

In France, the results of the PAQUID study revealed that 857,000 individuals aged 65 and over $(8.7 \%)$ had dementia, $80 \%$ were suffering from AD. It is estimated that over 225,000 new cases occur each year (2.3\% of the population aged 65 and over) [6]. This increase in the number of patients is not without consequences. Among the problems that have emerged are the ethical difficulty of making a very early diagnosis despite advances in biomarkers, the absence of an effective 'disease-modifying' therapy, and difficulties with assisting patients and their caregivers. Thus, the scientific community is confronted with the challenge of accelerating research, often using multicenter clinical trials with an international dimension, leading to high stakes.

France has been the second European country behind Scandinavia in terms of recruiting patients (400 patients/million people) for all pathologies [7]. Notably in the field of neuroscience and $\mathrm{AD}$, France has lost this place according to investigations by pharmaceutical companies performed in 2008. In 2010, France was far behind, with an average number of 27.7 recruited patients per study compared to 40.2 in Scandinavia and below the overall European figure of 28.2. With respect to the average speed, France is far behind Scandinavia at 0.7 versus 2.0, and below the European figure of 1.2 [8]. Since 2002, with the creation of Centers of Memory Resources and Research (CMRR) considerable improvements have been made in the administrative and institutional framework within which dementia is managed. Progress has been achieved by improving local organization, sharing experiences and establishing a national investigator network as it had already been done for the AD plan, which is strongly encouraging. The most emblematic change took place in March 2007 with the creation of a public interest group (GIP) supported by Interregional Clinical Research Delegations (DIRC) and known as the National Center for Managing Health Product Trials (CeNGEPS) lasting for a period of 4 years. Its objective was to maintain and increase the attractiveness of France for the conduct of clinical research $[9,10]$. 
The main aim of the present study was to look at factors that optimize inclusion in clinical trials on AD. Specific objectives were primarily to assess how the CMRR facilitate communication concerning clinical trials, to evaluate the internal organization of centers as it affects the dynamics of subject recruitment, and to evaluate the screening tools used in each CMRR.

\section{Methods}

\section{Study Design}

This was a descriptive national epidemiological survey involving all CMRR in France. This study was not interventional in that it did not affect the care of patients in the centers.

\section{Study Framework}

A CMRR is a center of memory resources and research that meets the criteria of the DHOS Circular of April 16, 2002, on the implementation of the action program for patients with AD or related conditions. Each CMRR is the subject of proceedings for certification by the regional hospital agencies. Currently, there are 27 CMRR in France including 25 in metropolitan areas. They have four missions: care, education, research and an entertainment network.

\section{Study Population}

The target population for this study consisted mainly of doctors, physician investigators and subinvestigators in all CMRR in France. To participate in the survey, subjects were required to be medically registered and to have worked for at least 1 year in a CMRR. Responses to the questionnaire received after the study period were excluded.

\section{Conduct of the Survey}

The survey was conducted over 3 months between May 1 and July 31,2011. A self-administered questionnaire covering three areas was used: (1) communication with health professionals about clinical trials, with the Center for Memory at Home (CMP) as well as with patients/caregivers and the general public; (2) internal organization and the existence and operation of a unit dedicated to trial enrollment, (3) and the evaluation of screening tools used in each CMRR. The survey was conducted in the following stages:

- $\quad$ stage 1: development of the questionnaire on the three main areas

- $\quad$ stage 2: testing of the questionnaire in a sample of five doctors

- $\quad$ stage 3: making contact with the CMRR in metropolitan France

- $\quad$ stage 4: distribution of the questionnaire by mail and e-mail

- $\quad$ stage 5: responses by mail from July 1, 2011

- $\quad$ stage 6: investigations closed on July 31, 2011

- stage 7: data management and statistical analysis.

\section{Data Management}

Data were managed by the functional unit of clinical research and biostatistics of the University Hospital of Limoges. The database was stored on a server at the University Hospital of Limoges and met all relevant safety standards (access protected by login and password). Consistency checks were made during data entry. At the end of the audit period, the database was closed and then exported using SAS ${ }^{\circledR}$ software version 9 (SAS Institute, Cary, N.C., USA) for statistical analysis. 
Fig. 1. Flow chart of reception mode and questionnaire analysis.

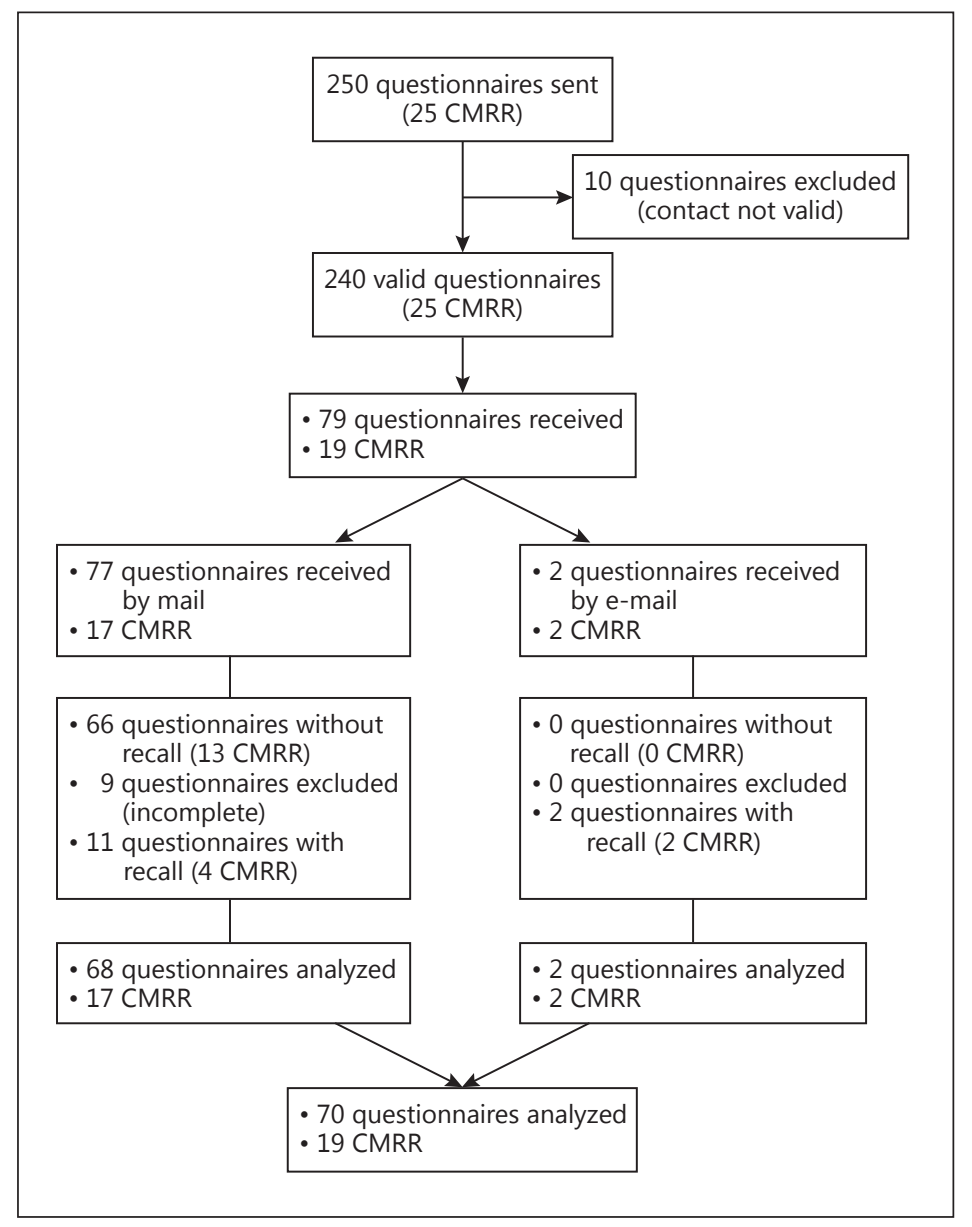

\section{Statistical Analysis}

The descriptive analysis of continuous variables (e.g. length of experience) is presented as mean, standard deviation, minimum and maximum or median, first and third quartile, eligible and missing data by subgroup and in total. Categorical variables (e.g. sex) are presented as number and percentage (expressed at two decimal places) by subgroup and total. To compare subgroups based on quantitative variables, Student's t test or analysis of variance (number of groups greater than two) was performed when normality was not rejected (Shapiro-Wilk), otherwise a nonparametric test such as Mann-Whitney or Kruskal-Wallis (number of groups greater than two) was preferred. To compare subgroups based on qualitative variables, a Pearson $\chi^{2}$ test was performed, and if the theoretical numbers were low, Fisher's exact test was used.

The significance level chosen for the overall alpha risk was $5 \%$ in the bilateral situation. Statistical analyses were performed using SAS software version 9.2 (SAS Institute).

\section{Results}

\section{Response Rate}

The participation rate was $76 \%$ (18 of 25 centers). A total of 250 questionnaires were sent to all medical officers, investigators or subinvestigators in CMRR (10 questionnaires per 
Tchalla et al.: Optimization of the Inclusion of Alzheimer's Disease Patients in Clinical Trials

Table 1. Sociodemographic characteristics of participants of a national descriptive survey for optimizing inclusion of patients in clinical trials on $\mathrm{AD}$

\begin{tabular}{lccc}
\hline Characteristics & $\begin{array}{l}\text { Medical managers } \\
(\mathrm{n}=10)\end{array}$ & $\begin{array}{l}\text { Medical investigators and } \\
\text { subinvestigators }(\mathrm{n}=60)\end{array}$ & $\begin{array}{l}\text { Total } \\
(\mathrm{n}=70)\end{array}$ \\
\hline $\begin{array}{l}\text { Age in years } \\
\quad 30\end{array}$ & 0 & $1(1.7 \%)$ & $1(1.4 \%)$ \\
$30-39$ & 0 & $33(55.0 \%)$ & $33(47.1 \%)$ \\
$40-49$ & $2(20.0 \%)$ & $12(20.0 \%)$ & $14(20.0 \%)$ \\
$50-59$ & $5(50.0 \%)$ & $13(21.7 \%)$ & $18(25.7 \%)$ \\
$\geq 60$ & $3(30.0 \%)$ & $1(1.7 \%)$ & $4(5.7 \%)$ \\
Women & $5(50.0 \%)$ & $37(61.7 \%)$ & $42(60.0 \%)$ \\
Years of medical experience & $26.5 \pm 6.0$ & $12.3 \pm 9.2$ & $14.4 \pm 10.1$ \\
Years of experience in CMRR & $1(10.0 \%)$ & $6(10.0 \%)$ & $6(8.6 \%)$ \\
$\quad<1$ & $8(80.0 \%)$ & $26(43.3 \%)$ & $26(37.1 \%)$ \\
$\quad 1-5$ & $1(10.0 \%)$ & $28(46.7 \%)$ & $38(54.3 \%)$ \\
$>5$ & & & \\
\hline
\end{tabular}

center). Two hundred and forty questionnaires reached the appropriate personnel and 10 were excluded. The return rate was $32.9 \%$ and the individual response rate was $29.2 \%$ (fig. 1 ).

\section{Characteristics of the Study Population}

The largest group of respondents was aged 30-39 years, representing 47.1\%. Sixty percent were women and half of them had a management role in a CMRR. In terms of initial training, neurologists were the most represented, accounting for $60 \%$; less than $30 \%$ were geriatricians and less than $10 \%$ were psychiatrists (table 1 ). The average length of practice of medicine was 12 years for clinical investigators and subinvestigators and 26 years among doctors in charge. As regards the length of experience in a CMRR, 54.3\% had more than 5 years of experience (table 1).

\section{Communication}

In total, $87.0 \%$ of the participants stated that their center communicated with health professionals in general, $88.9 \%$ with medical specialists (geriatricians, neurologists and psychiatrists), $84.1 \%$ with nearby memory centers, $73.0 \%$ with general practitioners, and $50.8 \%$ with independent neuropsychologists and speech therapists (table 2). Regarding the frequency of communication, $50.8 \%$ reported contacting general practitioners at least once a month but the figure was only $27.4 \%$ for speech therapists, $23.8 \%$ for neuropsychologists, $22.2 \%$ for physician specialists and $17.5 \%$ for nearby memory centers (table 2 ).

Approximately $94 \%$ of the respondents communicated with patients, mostly during consultations (88.6\%), and a few used billboards (35.7\%), brochures $(21.4 \%)$, newsletters $(12.9 \%)$ or the telephone $(11.4 \%)$. Collaboration with patient organizations and carers was effective in $75 \%$ of the cases, often involving briefings and awareness sessions (51.6\%) but very few attended workshops (14.1\%) or social events (12.5\%) (table 2).

Only half of the participants (54.4\%) communicated with the public occasionally or very often (46.9\%) and mainly did so via thematic conferences (37.5\%), but rarely via the Internet (18.8\%) or audiovisual media (12.5\%) (table 2).

\section{Internal Organization}

Approximately $78 \%$ of the participants claimed to have a specific research group in their CMRR. In most cases (75\%), this research group had a manager and often (39\%) comprised 
Table 2. Classification of CMRR communication parameters of a national descriptive survey for optimizing inclusion of patients in clinical trials on $\mathrm{AD}$

\begin{tabular}{llll}
\hline Communication parameters & $\begin{array}{l}\text { Medical } \\
\text { managers } \\
(\mathrm{n}=10)\end{array}$ & $\begin{array}{l}\text { Medical investigators } \\
\text { and subinvestigators } \\
(\mathrm{n}=60)\end{array}$ & $\begin{array}{l}\text { Total } \\
(\mathrm{n}=70)\end{array}$ \\
\hline Communication with health professionals & $10(100.0 \%)$ & $50(84.8 \%)$ & $60(87.0 \%)$ \\
Communication with patients & $10(100.0 \%)$ & $56(93.3 \%)$ & $66(94.3 \%)$ \\
Collaboration with patient and carer organizations & $7(70.0 \%)$ & $43(74.1 \%)$ & $50(73.5 \%)$ \\
Collaboration with other associations & $7(70.0 \%)$ & $19(35.9 \%)$ & $26(41.9 \%)$ \\
Communication with the general public & $6(60.0 \%)$ & $31(53.5 \%)$ & $37(54.4 \%)$ \\
\hline
\end{tabular}

Table 3. Classification of CMRR internal organization parameters of a national descriptive survey for optimizing inclusion of patients in clinical trials on AD

\begin{tabular}{llll}
\hline Internal organization parameters & $\begin{array}{l}\text { Medical } \\
\text { managers } \\
(\mathrm{n}=10)\end{array}$ & $\begin{array}{l}\text { Medical investigators } \\
\text { and subinvestigators } \\
(\mathrm{n}=60)\end{array}$ & $\begin{array}{l}\text { Total } \\
(\mathrm{n}=70)\end{array}$ \\
\hline Specific unit dedicated to clinical research & $8(80.0 \%)$ & $46(78.0 \%)$ & $54(78.3 \%)$ \\
Receiving e-mails on the progress of the inclusions & $5(62.5 \%)$ & $30(53.6 \%)$ & $35(50.7 \%)$ \\
Updated register of potential investigators or subinvestigators & $6(60.0 \%)$ & $27(46.6 \%)$ & $33(48.5 \%)$ \\
Consultation time dedicated to inclusions & $8(80.0 \%)$ & $30(50.9 \%)$ & $38(55.1 \%)$ \\
\hline
\end{tabular}

fewer than four members (table 3). This group met regularly in most cases (82.3\%). Meetings focused primarily on information about upcoming clinical trials (86\%), the progress of trials already underway (85\%) and multidisciplinary issues (70\%). Only half of the participants reported receiving the minutes of meetings, including reports on the progress of enrollment. In $35.3 \%$ of the cases, participants reported that their center did not have a record of physician investigators. More than half of the participants (55\%) did not have a consultation time dedicated to enrollment (table 3).

\section{Assessment of Screening Tools}

A total of $76.5 \%$ of the participants reported having a screening tool, but only $27.4 \%$ were satisfied with it. In nearly $35 \%$ of the cases, nobody was assigned to enter data, and problems (essentially the time taken to complete it and inadequacy of the tool) were noted in $36 \%$ of the cases (table 4). In centers with no screening tools, $65 \%$ of the patients were recruited during consultations and $29 \%$ by review of the relevant records and correspondence. A total of $43 \%$ gave their consent for future involvement during consultations (table 4).

\section{Discussion}

\section{Main Results}

This study shows that several factors play a role in rendering the recruitment of $A D$ patients in clinical studies inefficient and in opening a framework for improvement. Three quarters of all CMRR participated in our survey, and about one third of the surveyed physicians responded positively. The results showed that the majority of the CMRR communicated 
Table 4. Screening tools evaluation of a national descriptive survey for optimizing inclusions of patients in clinical trials on $\mathrm{AD}$

\begin{tabular}{llll}
\hline Parameter evaluation & $\begin{array}{l}\text { Medical } \\
\text { managers } \\
(\mathrm{n}=10)\end{array}$ & $\begin{array}{l}\text { Medical investigators } \\
\text { and subinvestigators } \\
(\mathrm{n}=60)\end{array}$ & $\begin{array}{l}\text { Total } \\
(\mathrm{n}=70)\end{array}$ \\
\hline Specific screening tools & $7(70.0 \%)$ & $45(75.0 \%)$ & $52(74.3 \%)$ \\
$\quad$ Specific person for entering data & $5(71.4 \%)$ & $37(82.2 \%)$ & $42(80.7 \%)$ \\
Not satisfied with this tool & $1(14.3 \%)$ & $31(68.9 \%)$ & $32(61.5 \%)$ \\
Time-consuming tools & $2(28.6 \%)$ & $17(37.8 \%)$ & $19(36.5 \%)$ \\
Unadapted tools & $3(42.9 \%)$ & $15(33.3 \%)$ & $18(34.6 \%)$ \\
Other & 0 & $2(4.4 \%)$ & $2(3.9 \%)$ \\
No specific screening tools & $3(30.0 \%)$ & $15(25.0 \%)$ & $18(25.7 \%)$ \\
Retrospective reading of consultation report or hospital day report & $1(33.3 \%)$ & $11(73.3 \%)$ & $12(66.7 \%)$ \\
Following consultations & $2(66.7 \%)$ & $14(93.3 \%)$ & $16(88.9 \%)$ \\
Medical staff & $1(33.3 \%)$ & $11(73.3 \%)$ & $12(66.7 \%)$ \\
Satisfied with this mode of operation & $3(100.0 \%)$ & $13(86.7 \%)$ & $16(88.9 \%)$ \\
\hline
\end{tabular}

with health professionals but very irregularly. Communication with patients was also reported, but it was inadequate and ineffective, as was collaboration with patient associations and/or caregivers. A net deficit of communication with the large public is observed and the diffusion method was discontinued. The internal organization of the group was based on existing research in most cases but was active in only half of the cases. Three quarters of the respondents had a screening tool in their CMRR but over half were not satisfied with it.

\section{Strengths}

This survey was carried out using a protocol suited to the use of a pretested questionnaire and focused on three specific areas: communication, internal organization and the screening tool. The diffusion method was optimal by mail and mail with a telephone reminder. This method maximizes the rate of participation in large-scale surveys [11]. Our distribution also relies on local representatives in the centers. All CMRR in France were asked to participate, and the response was overwhelming.

\section{Limitations}

Like most national surveys, this study has some shortcomings including the participation rate and the lack of an individual exhaustive survey of all members of each center. The individual response rate was relatively low but still within the acceptable range for surveys conducted nationally.

\section{External Consistency}

Several studies [12-14] analyzing the predictors of optimal inclusion of patients in clinical trials confirm our hypothesis of internal and external testing. This study focuses on the factor of external health care professionals, patients and caregivers. This is an element that leads to substantial research on centers and the immediate environment of patients. This factor is associated with an OR of 4.0 and a 95\% CI of 1.1-15.6 [14]. Other authors have shown that the involvement of carers and/or professionals with better information increased the inclusion rate by $27 \%$ [15]. Consideration of the patient's environment and appropriate communication are crucial in the optimization of recruitment in clinical trials with an impact on AD [16]. These elements support our aim of optimizing the communication and collaboration between CMRR, patient organizations and caregivers, and allowing the public access 
to information, including information on clinical trials and their inclusion criteria. An electronic portal (ONRA) for all ongoing trials in French CMRR, like clinicaltrials.gov, would also optimize communication regarding the general public and have direct implications for familiarization with research; it would also create a personal incentive for patients and families to contact research centers $[17,18]$. For more effective communication, the internal organization of the research center should be clearly arranged. Therefore, it is essential to establish clear procedures for the organization of inclusions.

The internal organization concerning group research should be well defined in terms of its mode of operation and its composition. Our study reveals that most centers have a research group but it is often inactive and therefore ineffective. Galvin et al. [14] showed that inadequate procedures and the framework of opinion about the process of inclusions are both predictors of inclusion: OR 4.7, 95\% CI (12-18.7), OR 6.8, 95\% CI (1.4-32.3). Diebolt and Pletan [19] clearly showed that the internal organization of research centers in France has major deficiencies particularly with regard to bureaucracy and lack of motivation of practicing physicians in the centers. They do not feel involved in the procedures because of a lack of staff meetings or information on research concerning upcoming clinical trials or the progress of trials already underway. The discrepancy between the results we obtained in this investigation and the perceptions of CMRR managers and physician-investigators and coinvestigators illustrate this lack of standardization of procedures in the same center. Apart from purely organizational issues, the quality of screening tools requires special attention.

The evaluation of screening tools performed as part of this investigation shows that they were available in most centers but were generally unsatisfactory. The main problems were the lack of personnel responsible for data entry and the inadequate functionality of the tools themselves. These deficiencies have resulted in time-consuming inclusions that not only directly reduce the speed of recruitment but also impair the ability to recruit patients meeting various inclusion criteria.

\section{Conclusion}

The information provided by this survey offers a basis for improvement in the screening of patients via both development of internal organization and adaptation of tools that are already available. This means promoting regular communication that is appropriate and targeted to health professionals, nearby memory centers, associations and the general public and thereby familiarizing the French population with clinical research in the field of AD.

\section{Acknowledgements}

We thank all participants of this survey, the France Alzheimer Plan Foundation and its leaders Prof. Joël Menard and Hervé Maisonneuve.

\section{Disclosure Statement}

The authors have no conflicts of interest to disclose. 


\section{References}

1 Ferri CP, Prince M, Brayne C, et al: Global prevalence of dementia: a Delphi consensus study. Lancet 2005;366: 2112-2117.

-2 Wimo A, Jönsson L, Gustavsson A, et al: The economic impact of dementia in Europe in 2008-cost estimates from the Eurocode project. Int J Geriatr Psychiatry 2011;26:825-832.

3 Knapp M, Prince M, Albanese E, et al: For Kings' College London and London School of Economics. London: Alzheimer's Society, Gordon House. Available at http://www.alzheimers.org.uk/site/scripts/download_info. php?fileID52, 2007.

4 Handels RLH, Wolfs CAG, Aalten P, et al: Determinants of care costs of patients with dementia or cognitive impairment. Alzheimer Dis Assoc Disord 2013;27:30-36.

$\checkmark 5$ Wadman M: US government sets out Alzheimer's plan. Nature 2012;485:426-427.

6 OPEPS: Rapport sur la maladie d'Alzheimer et les maladies apparentées. Paris, La Documentation française, 2005, p 256.

7 D’Enfert J, Lassale C, Prod'homme P, et al: Attractivité de la France pour les essais cliniques: évaluation par les laboratoires promoteurs. Thérapie 2003;58:283-289.

-8 Lassale C, Sibenaler C, Béhier JM, et al: La France, un pays attractif pour la recherche clinique internationale: enquête 2008 du Leem. Thérapie 2008;63:345-357.

-9 Courcier S, Sibenaler C, Couderc M, et al: La France est un pays attractif pour la recherche clinique internationale: enquête 2006 du Leem. Thérapie 2006;61:407-418.

10 Courcier-Duplantier S, Bouhours P, Pinton P, et al: Attractivité de la France pour la recherche clinique internationale: une étude du Leem dresse un constat peu favorable et suggère des voies d'amélioration. Thérapie 2004;59:629-638.

11 Harris TJ, Carey IM, et al: Optimising recruitment into a study of physical activity in older people: a randomised controlled trial of different approaches. Age Ageing 2008;37:659-665.

12 Mainous G, Smith D, Geesey M, et al: Factors influencing physician-referrals of patients to clinical trials. J Natl Med Assoc 2008;100:1298-1303.

13 Dev A, Kauf T, Zekry A, et al: Factors influencing the participation of gastroenterologists and hepatologists in clinical research. BMC Health Serv Res 2008;8:208.

14 Galvin JE, James E, Meuser TM, Boise L, Connell CM: Predictors of physician referral for patient recruitment to Alzheimer disease clinical trials. Alzheimer Dis Assoc Disord 2009;23:352-356.

15 Karlawish J, Cary M, Rubright J, TenHave T, et al: How redesigning AD clinical trials might increase study partners' willingness to participate. Neurology 2008;71:1883-1888.

16 Carr A, Davis R, Spencer D, et al: Comparison of recruitment efforts targeted at primary care physicians versus the community at large for participation in Alzheimer's disease clinical trials. Alzheimer Dis Assoc Disord 2010;24:165-170.

17 Andrieu S, Coley N, Gardette V, et al: Representations and practices of prevention in elderly populations: investigating acceptance to participate in and adhesion to an intervention study for the prevention of Alzheimer's disease (ACCEPT study) - the need for a multidisciplinary approach. J Nutr Health Aging 2012;16:352-354.

$\$ 18$ Carrié I, Van Kan GA, Gillette-Guyonnet S, et al: Recruitment strategies for preventive trials. The MAPT study (MultiDomain Alzheimer Preventive Trial). J Nutr Health Aging 2012;16:355-359.

19 Diebolt V, Pletan Y: How to improve clinical research performances in France? Thérapie 2008;63:297-300. 